\title{
Tidal pacing, skipped slips and the slowdown of Whillans Ice Stream, Antarctica
}

\author{
J. Paul WINBERRY, ${ }^{1}$ Sridhar ANANDAKRISHNAN, ${ }^{2}$ Richard B. ALLEY, $^{2}$ \\ Douglas A. WIENS, ${ }^{3}$ Martin J. PRATT ${ }^{3}$ \\ ${ }^{1}$ Department of Geological Sciences, Central Washington University, Ellensburg, WA, USA \\ E-mail: winberry@geology.cwu.edu \\ ${ }^{2}$ Department of Geosciences, The Pennsylvania State University, University Park, PA, USA \\ ${ }^{3}$ Department of Earth and Planetary Sciences, Washington University in St Louis, St Louis, MO, USA
}

\begin{abstract}
We summarize new observations of the deceleration and stick-slip motion of Whillans Ice Stream (WIS), Antarctica. We refine the location of the large sticky spots that resist motion between slip events, the locations of which are controlled by the patterns of subglacial water flow. Our examination of the long-term velocity time series for the ice stream reveals that the decadal-scale deceleration is not occurring at a steady rate, but varies at the sub-decadal timescale. This unsteady deceleration modulates the temporal evolution of a broad ( $50 \mathrm{~km}$ across) surface-elevation bulge forming at the junction between the relatively narrow upstream portion of the ice stream and broad ice plain that constitutes the downstream end of WIS. Comparison of observations from April 2003 and November 2010 reveals significant changes in the tidally modulated stick-slip cycle that regulates motion on the ice plain. We observe that the timing of slip events has become less regular in response to decreased flow speed in the upstream portions of the ice stream. The decreased regularity of slip events has reduced the release of stored elastic strain during slip events, increasing the rate of deceleration.
\end{abstract}

KEYWORDS: Antarctic glaciology, ice dynamics, ice streams, subglacial lakes

\section{INTRODUCTION}

Fast-moving ice-streams and outlet glaciers form the major pathways for ice exiting the Antarctic continent; thus, their behavior exerts a dominant control on the mass balance of the Antarctic ice sheets (Shabtaie and Bentley, 1987). However, far from being stable features, these fast-flowing regions of an ice sheet may exhibit fluctuations at a range of timescales. For example, the Siple Coast ice streams exhibit major century-scale shifts, driven by feedbacks in subglacial meltwater production and routing, producing periods of rapid motion (hundreds of $\mathrm{m} \mathrm{a}^{-1}$ ) and stagnation (Vogel and others, 2005; Hulbe and Fahnestock, 2007). At the other end of the time spectrum, large $(\sim 100 \%)$ fluctuations of icestream velocity on a timescale of hours are observed near their grounding lines where elevated subglacial water pressures make the ice streams sensitive to small forcebalance perturbations resulting from the rise and fall of the ocean tides (Anandakrishnan and others, 2003; Gudmundsson, 2006; Wiens and others, 2008; Walter and others, 2011; Winberry and others, 2011). A detailed understanding of the mechanisms regulating fluctuations in ice-stream behavior at all timescales, as well as the interactions across timescales, is needed to understand the evolution of ice sheets.

Whillans Ice Stream (WIS), a major drainage path of the West Antarctic ice sheet, exemplifies the temporal complexity of ice-stream behavior. Repeat measurements of velocity since the 1970s have documented a $\sim 50 \%$ reduction in flow speed, indicating the ice stream may stagnate by the end of this century (Stephenson and Bindschadler, 1988; Bindschadler and others, 2005; Joughin and others, 2005). Complicating our understanding of this stagnation, however, is the relatively recent observation that the downstream portion of the ice stream accomplishes most of its motion during twice-daily $30 \mathrm{~min}$ bursts of motion, remaining largely stagnant the remainder of the day (Bindschadler and others, 2003).

In this contribution, we provide an updated overview of the dynamic behavior as well as ongoing changes occurring in the downstream portion of the ice stream, where WIS merges with Mercer Ice Stream to form a broad $(\sim 100 \mathrm{~km})$ low-slope ice plain (Fig. 1). In Section 2, we document new details about the sticky spots that are thought to be responsible for stick-slip motion, and review the tidal pacing of the stick-slip cycle. In Section 3, we explore ongoing changes in ice-stream behavior, including longterm deceleration and surface-elevation changes and how these are related to stick-slip motion.

\section{THE TIDALLY PACED STICK-SLIP BEHAVIOR OF WHILLANS ICE STREAM}

\subsection{Sticky-spot locations}

Similar to the motion on an earthquake fault, it has been proposed that the irregular stick-slip motion on the downstream portion of WIS is caused by small regions of high basal friction (sticky spots or asperities) at the ice/bed interface (Winberry and others, 2011). The strength of a sticky spot may balance the local driving stress and stress transmitted from surrounding regions, and under some conditions this can inhibit the stable sliding generally observed on ice streams (e.g. Zoet and others, 2013). In this model, between slip events, the relatively well-lubricated regions surrounding the sticky spot continue to move, producing elastic strain that results in an increasing applied shear stress on the sticky spot. When the applied shear stress exceeds the yield strength of the sticky spot, a slip event initiates. Rapid motion during the slip event dissipates the stored elastic potential energy, and, after motion stops, the 


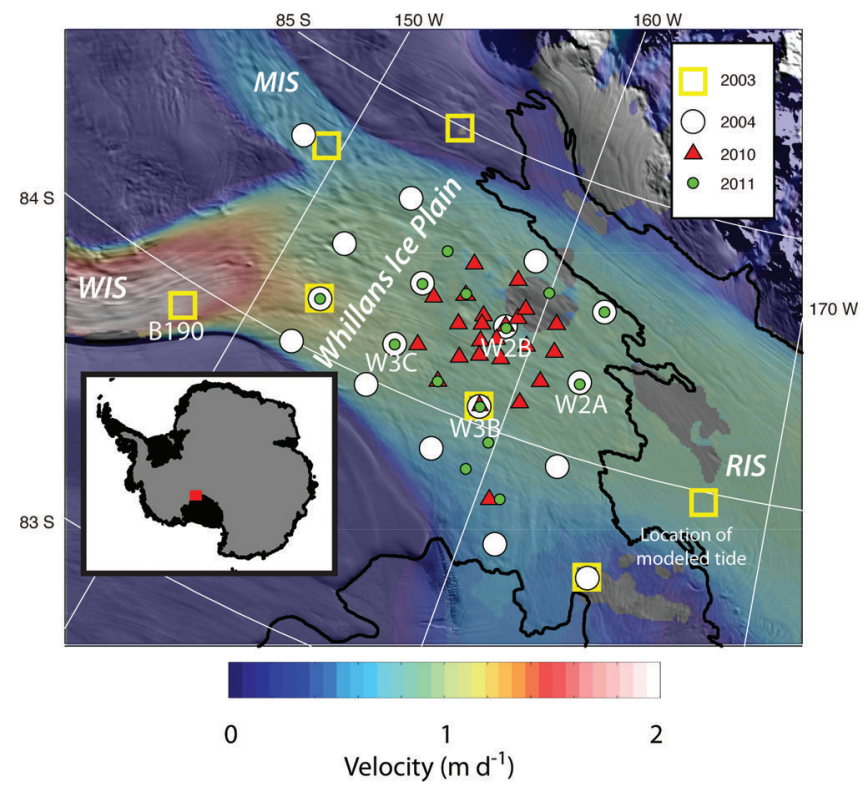

Fig. 1. The downstream portion of WIS. Inset shows location relative to the Antarctic continent. Colors show InSAR-derived mean surface flow speeds in 2009 (Rignot and others, 2011) draped over the Moderate Resolution Imaging Spectroradiometer (MODIS) mosaic of Antarctica. Thin black line is grounding line (Scambos and others, 2007). Locations and dates of GPS occupations are shown. Several sites discussed in the text are labeled. WIS: Whillans Ice Stream; MIS: Mercer Ice Stream; RIS: Ross Ice Shelf.

cycle of stress accumulation starts anew. However, later in the paper, we show that viscous processes are likely important in understanding the WIS stick-slip motion.

In our earlier studies on WIS, isolating the location(s) of the sticky spot(s) was hampered by the relatively coarse spatial resolution of our GPS observations $(\sim 50 \mathrm{~km})$ collected during 2003/04 (four sites, $\sim 130$ days) and 2004/05 (20 sites, 440 days). To overcome this limitation, we deployed a relatively dense ( $\sim 10 \mathrm{~km}$ spacing) network of GPS near the center of the ice stream during the 2010/11
(25 sites, $\sim 60$ days) and 2011/12 (14 sites, $\sim 21$ days) austral summers (Fig. 1). The GPS datasets were processed using Precise Point Positioning methods (Zumberge and others, 1997). Figure 2 shows the displacement time series at three stick-slip locations occupied in both 2004 and 2011. We found these sites to be suitably representative, with respect to both space and time.

A location of higher basal friction associated with a sticky spot has less inter-event motion than surrounding areas. For example, stations W3C and W2B have comparable mean velocities, but $\mathrm{W} 3 \mathrm{C}$ moves more than $\mathrm{W} 2 \mathrm{~B}$ between slip events; we infer from this lower percentage of stick-slip motion at W3C that its bed is better lubricated. To examine the spatial pattern of slipperiness, we separate each displacement record into its inter-event and slip-event components and use these to determine the percentage of total motion that occurs during slip events at each location (Fig. 2). To provide the most spatially comprehensive view, we also include observations from 2004 that were not reoccupied in 2010/11. While some changes in flow occurred between the two time periods, as discussed below, this does not alter the first-order patterns of percent stick-slip (Fig. 3a).

The entire lower portion of the ice stream is characterized by relatively high values of percent stick-slip motion. However, the data show two broad maxima in stick-slip motion (displacement during slip events as a fraction of total motion), with values as high as $90 \%$, which we call the central sticky spot (CSS) and the northern sticky spot (NSS). The CSS is shifted slightly from the location presented in previous work (Wiens and others, 2008; Winberry and others, 2011), but within the uncertainty given the coarse nature of the previous surveys. The CSS fails during the first part of slip events and is the location of maximum total slip during slip events. The NSS fails during the second half of slip events, after significant motion over the CSS has occurred (Winberry and others, 2011).

Large sticky spots like those imaged in Figure 3a may result from several different mechanisms (Alley, 1993). WIS is likely underlain by an extensive layer of till (unconsolidated sediment) (Blankenship and others, 1987; Kamb, 2001). The
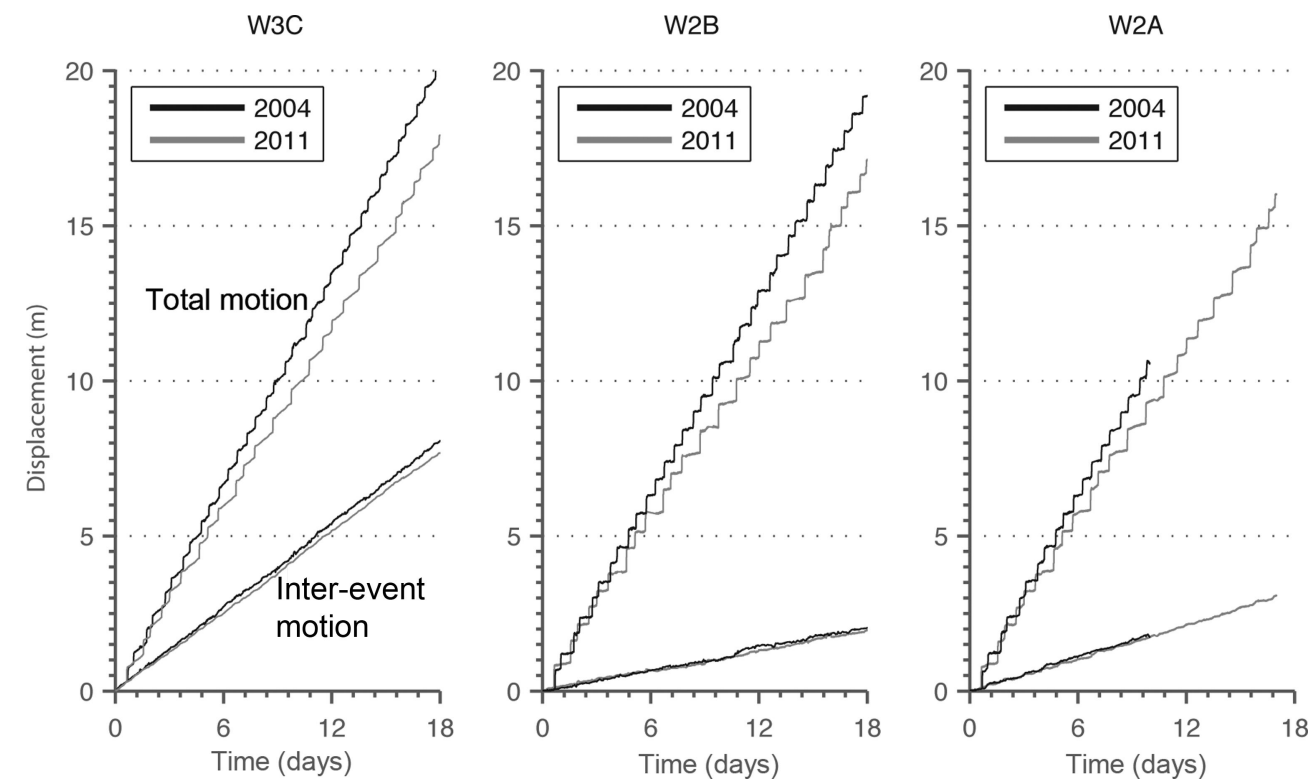

Fig. 2. Example GPS displacement time series for three stick-slip locations on WIS that were occupied during both 2004 and 2011. Lower time series show the inter-event component of motion by subtracting all motion that occurs during slip events. 
sensitivity of till properties to water pressure allows for a sticky spot to be associated with a relatively water-starved region where the low effective normal pressures required to sustain stable sliding cannot be maintained. Thus, we calculate the hydrostatic hydraulic potential $\Phi$ beneath WIS assuming near-zero effective pressure:

$$
\Phi=\rho_{\mathrm{i}} g z_{\mathrm{s}}-\left(\rho_{\mathrm{w}}-\rho_{\mathrm{i}}\right) g Z_{\mathrm{b}}
$$

where $\rho_{\mathrm{i}}$ and $\rho_{\mathrm{w}}$ are the densities of ice and water respectively, $g$ is acceleration due to gravity, while $z_{\mathrm{s}}$ and $z_{b}$ are the ice-sheet surface and bed elevations respectively (Shreve, 1972) using data from the Bedmap2 project (Fretwell and others, 2013).

Both sticky spots are associated with broad ridges that will tend to divert upstream subglacial water around these locations and increase effective pressure, consistent with the idea that, in this setting, stable sliding is inhibited by relatively high effective normal pressures (Fig. 3b). Thus, the present geometry of the ice stream directs the influx of upstream water required to maintain fast-flowing conditions (Parizek and others, 2002) away from the sticky spots into neighboring subglacial lakes (Fig. 3b; Fricker and Scambos, 2009).

The initiation of a WIS slip event and the subsequent rupture across the stick-slip region are complex (Wiens and others, 2008; Sergienko and others, 2009; Walter and others, 2011; Winberry and others, 2011), and a detailed discussion of these is beyond the scope of this contribution. Events occur just after high tide and just before low tide (described further below). Far-field seismic observations (hundreds of km away from WIS) detect two packets of energy during high-tide events, and three packets during low-tide events. Analysis of the rupture propagation during slip events by Pratt and others (2014) has identified three additional asperities that generate these packets of far-field seismic energy (labeled in Fig. 3a). All are located along the grounding line, and, although not directly associated with regions of measured minimum interevent slip, the large energy radiation during events shows that they are regions of high basal friction. During the initiation of low-tide events, failure of asperity 1 radiates the first packet of far-field seismic energy observed; however, during high-tide slip events, failure of asperity 1 is not abrupt enough to generate teleseismic waves. During both high-tide and lowtide slip events, rapid reaccelerations of the ice stream originate from the sites labeled 2 and 3 in Figure $3 a$, at the northern edge of the NSS, to produce the other packets of farfield seismic energy.

\subsection{The tidally paced stick-slip cycle}

WIS typically has had two slip events per day, one just after high tide and one just before low tide; for simplicity, we refer to these as 'high-tide' and 'low-tide' events (Fig. 4). The pattern is not completely regular and is changing, as discussed below. Bindschadler and others (2003) observed that the timing between slip events is variable due to the tidal pacing of inter-event stress accumulation rate (Fig. 4). Because both events typically occur on the falling tide and the tide is dominantly diurnal in this region, a high-tide event typically follows a relatively long inter-event period (14-19 hours), with a shorter inter-event period ( $<9$ hours) for lowtide events. Low-tide events are occasionally skipped, but we have not observed a skipped high-tide event. Additionally, during the neap tide the tidal phasing becomes less pronounced and the timing between slip events approaches the regular 12 hours (Winberry and others, 2009).
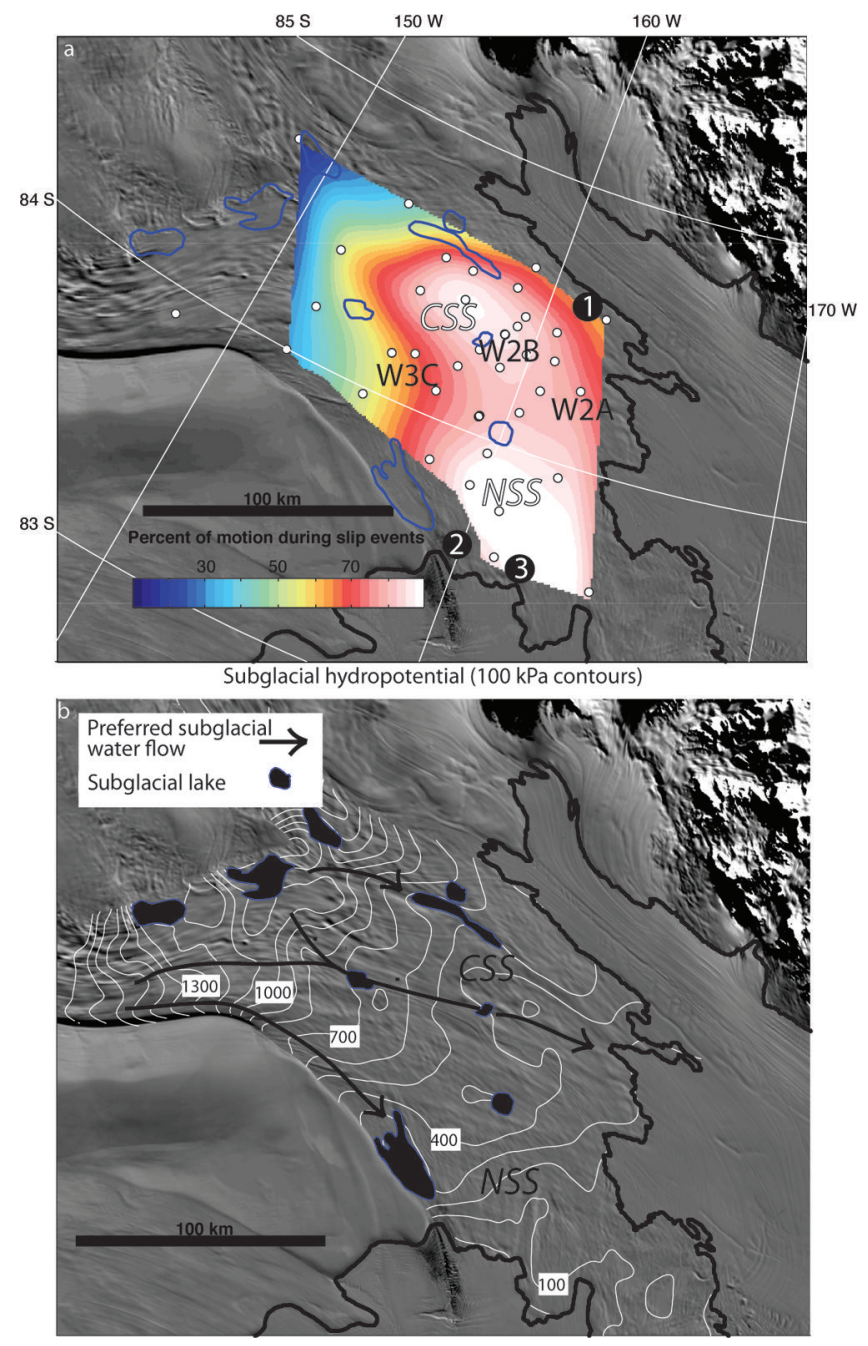

Fig. 3. Sticky-spot locations and active subglacial lakes. (a) Spatial pattern of percent of total motion occurring during stick-slip events. High values associated with sticky spots are identified by CSS (central sticky spot) and NSS (northern sticky spot). Black dots numbered 1,2 and 3 show the three asperities that generate farfield seismic energy (Pratt and others, 2014). (b) Subglacial hydrostatic hydraulic potential. Black polygons outline known active subglacial lakes (Fricker and others, 2007), and preferred flow paths for subglacial water determined from hydraulic potential gradients (Carter and others, 2013).

The tidal pacing of slip-event initiation arises from the modulation of flow speed near the grounding line (Anandakrishnan and others, 2003; Gudmundsson, 2006; Winberry and others, 2011). Figure 5 shows the displacement time series for locations that display the range of stick-slip behavior for three consecutive stick-slip cycles observed in 2011. Station W3C is characterized by steady motion during inter-event periods, characteristic of sites upstream and transverse of the CSS. In contrast, near the grounding line (W2A) the ice stream moves more quickly on a falling tide in response to the changing force budget associated with Ross Sea tides. Thus, in general, during the spring tides, a relatively short inter-event period is favored after a high-tide event, due to the relatively higher rates of strain accumulation. However, a low-tide slip event will occasionally fail to nucleate near the transition to the rising tides; the subsequent tidally controlled slowing of motion at the downstream end then delays the next slip event until just after the subsequent high tide. 

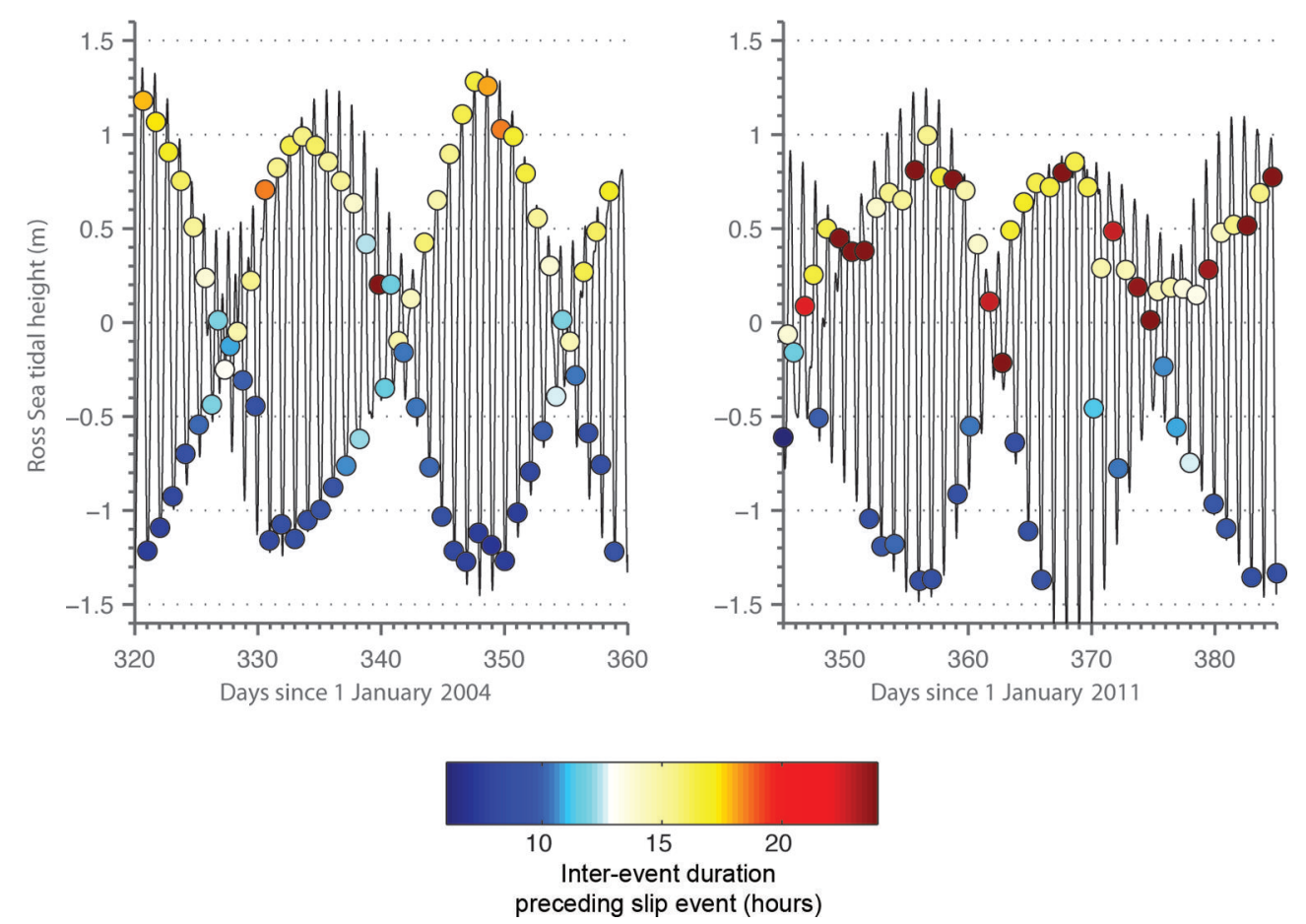

Fig. 4. Tidal pacing of slip events as detected by GPS sensors in WIS. Ross Sea tides at location just downstream of the grounding line (Fig. 1) are calculated using the CATS (Circum-Antarctic Tidal Simulation) model (Padman and others, 2003). Occurrences of slip events are denoted by circles, with colors indicating the inter-event duration preceding the slip event. Note the relatively high number of skipped low-tide events in right panel $(2011 / 12)$.

A second dominant control on the stick-slip cycle has been hypothesized to be a time-dependent strengthening of the subglacial interface following a slip event (Winberry and others, 2009). Such 'healing' behavior, strengthening the interface over time, is observed in laboratory studies (Marone, 1998; Zoet and others, 2013) and is inferred for repeating earthquakes beneath the head of David Glacier, Antarctica (Zoet and others, 2012). Beneath WIS, a strengthening mechanism could be related to sediment properties, such as pore-pressure diffusion or regelation

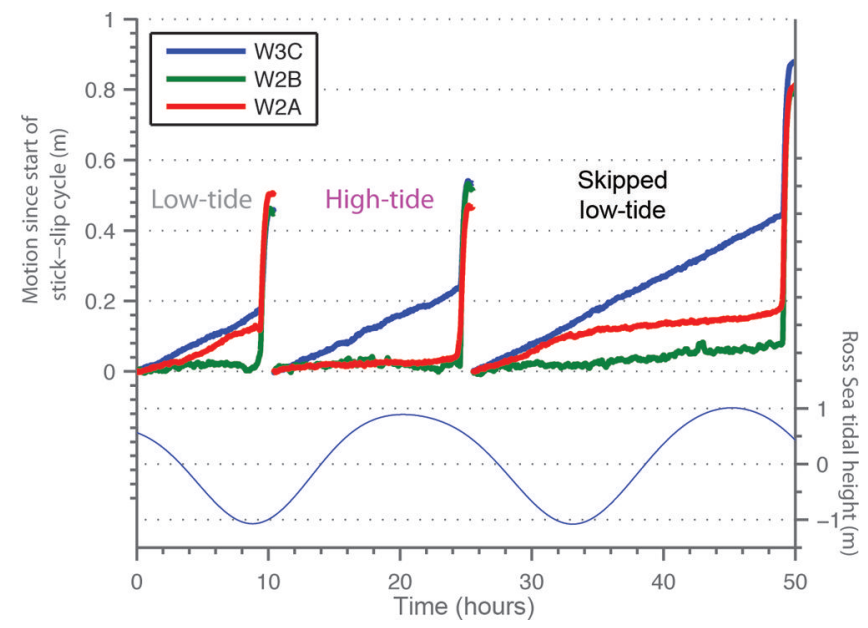

Fig. 5. Tidal pacing of shear stress accumulation. The displacement time series for stations W3C, W2B and W2A for three consecutive slip events observed during 2011. Bottom panel shows Ross Sea Tidal amplitude (Padman and others, 2003). Note the reduction of flow speed at W2A following the onset of a rising tide during the third stick-slip cycle. For visual clarity, following the termination of each slip event, displacement is reset to zero. into the bed (Alley, 1993; Iverson, 2010) or perhaps to thermal processes (Zoet and others, 2013). A time-dependent yield stress has been proposed to explain the observations that slip events that initiate following longer interevent periods result in higher displacements due to the larger stress drops (Fig. 6). Thus, it is likely that short interevent durations are favored on falling tides by both rapid stress accumulation and by the time-dependent strength of the sticky spot that allows slip-event initiation at a lower yield stress.

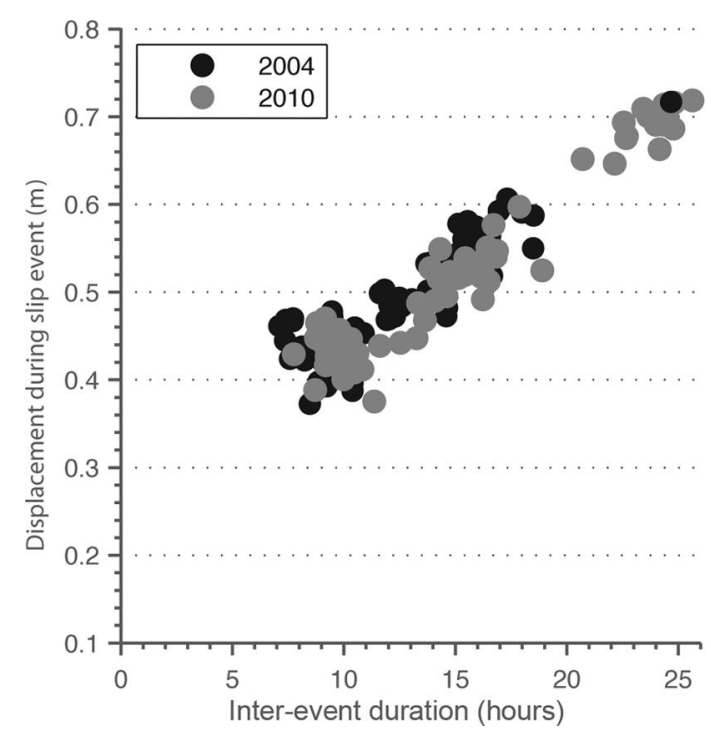

Fig. 6. The relationship between displacement occurring during a slip event and the inter-event duration preceding the slip event at station W2B. 

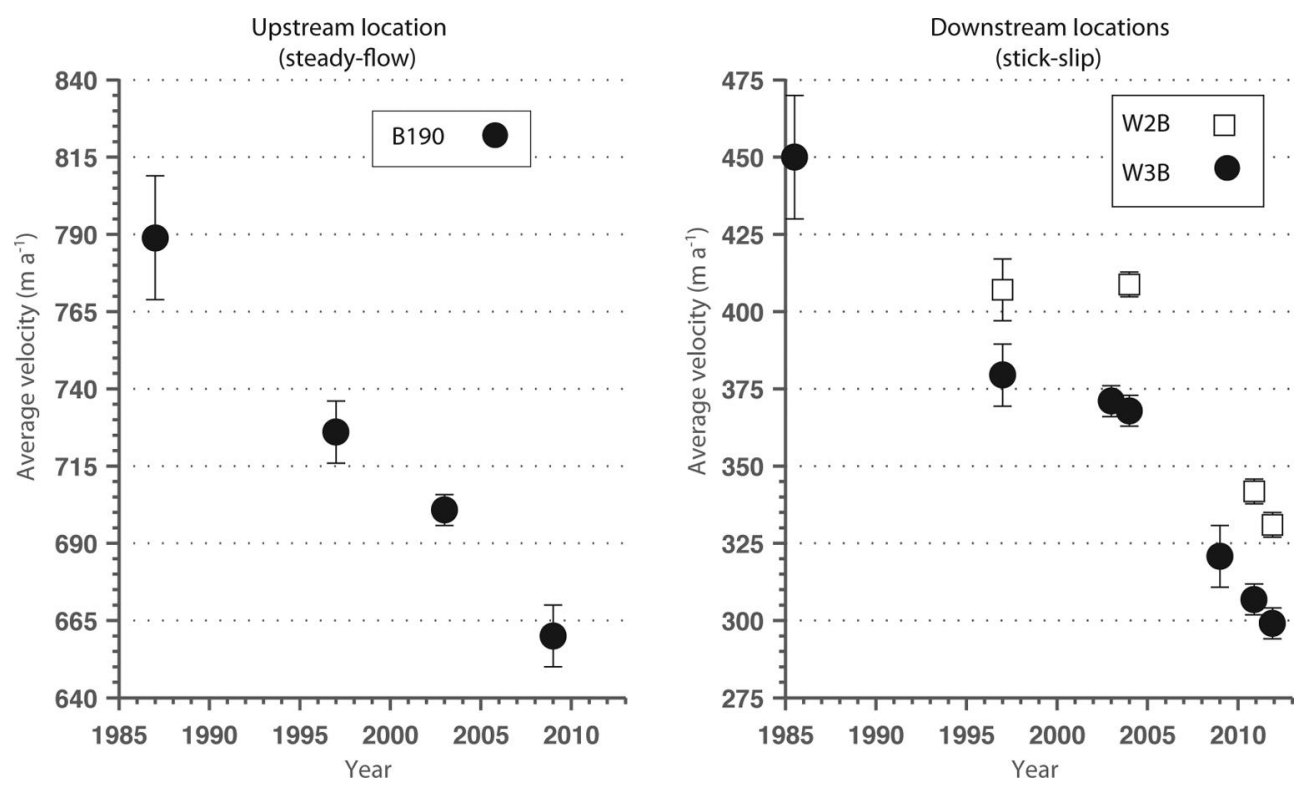

Fig. 7. Long-term deceleration of WIS at non-stick-slip and two stick-slip locations from GPS observations.

\section{OBSERVED CHANGES IN DECELERATION, STICK-SLIP AND SURFACE ELEVATION}

Inspection of displacement time series reveals several changes in the ice stream's behavior between 2003/04 and 2010/11 (Fig. 2). The most prominent change is the continued deceleration of the ice stream. Closer scrutiny also reveals changes in the regularity of the stick-slip cycle of the ice stream, with an increasing tendency to skip lowtide slip events (Fig. 4). In this section, we discuss changes in ice-stream behavior and geometry observed with both in situ and satellite instruments.

\subsection{Flow-speed changes}

The long-term deceleration of WIS has been well documented in several previous studies (Joughin and others, 2002, 2005; Stearns and others, 2005; Scheuchl and others, 2012) and has been linked to reduction in basal meltwater production, increasing strength of the underlying till, which in turn reduces basal motion (e.g. Bougamont and others, 2003). Our goal is to provide an updated compilation, including both spaceborne and field observations collected during the past 15 years, to elucidate any temporal complexity in the deceleration trend in the downstream portion where stick-slip motion dominates, with our findings similar to those recently reported by Beem and others (2014).

The Siple Coast Project (SCP) in the 1980s made repeat measurements of stake locations by Transit satellite receivers, with an uncertainty of $\sim 25 \mathrm{~m} \mathrm{a}^{-1}$ (Whillans and others, 1987; Stephenson and Bindschadler, 1988; Bindschadler, 1993). More-recent point measurements of velocity have relied on continuous GPS observations. Mean annual velocities of stick-slip locations can be obtained by fitting a linear trend to the time series; uncertainties vary (due to length of occupation) but are small $\left(<5 \mathrm{~m} \mathrm{a}^{-1}\right)$ (Joughin and others, 2005). Additionally, during 1997 and 2009, interferometric synthetic aperture radar (InSAR) observations of WIS provided spatially continuous observations of velocities not possible with stake occupation methods (Joughin and others, 1999; Rignot and others, 2011), with uncertainties of $20 \mathrm{~m} \mathrm{a}^{-1}$.

Flow speed histories can be constructed at discrete locations on WIS by coupling the InSAR observations with
SCP measurements and subsequent GPS stake observations that are in close proximity to each other. Repeat GPS observations were made at the same geographic location (i.e. not by reoccupation of a stake that was advected downstream between observation periods). Figure 7 shows one example from an upstream location (B190) in the main trunk of WIS, upstream of the stick-slip region, and one downstream on the ice plain, characterized by stick-slip behavior (W3B). We also plot the shorter time series for an additional downstream stick-slip location (W2B) that is more centrally located but not near a SCP site. Each of these time series shows the prominent deceleration, an average of $\sim 4-6 \mathrm{~m} \mathrm{a}^{-2}$, reported in previous work (Joughin and others, 2002; Bindschadler and others, 2005).

The notable feature of the recent study by Beem and others (2014) and our compilation is the observation that the rate of deceleration on the ice plain was smaller between 1997 and 2004 than before and after. Stations in the downstream portion of WIS display modest rates of deceleration $\left(0-1 \mathrm{~m} \mathrm{a}^{-2}\right)$ between 1997 and 2004, relative to the long-term rates $\left(4-6 \mathrm{~m} \mathrm{a}^{-2}\right)$. Repeat GPS measurements at W3B in 2003 and 2004 show an intermediate deceleration of $\sim 3 \mathrm{~m} \mathrm{a}^{-2}$, followed by a return to relatively high deceleration rates $\left(\sim 9 \mathrm{~m} \mathrm{a}^{-2}\right.$ or greater) between 2004 and 2009. Repeat GPS measurements at W3B and W2B document a rate of $\sim 11 \mathrm{~m} \mathrm{a}^{-2}$ between 2010 and 2011. In contrast to these downstream locations, upstream site B190 exhibits a steadier deceleration; the 1997-2003 rate may have a slightly lower magnitude than the long-term trend, but within the uncertainties in the InSAR datasets.

\subsection{Skipped slips and their influence on mean flow speed}

As discussed in earlier work (Winberry and others, 2011) and below, inter-event strain is predominately accumulated between the smooth-flowing upstream portion of the ice stream and the sticky spot located in the center of the ice plain (CSS, Fig. 3). This leads to the expectation that longterm rates of deceleration in the stick-slip portion of WIS should mimic those observed upstream in the steady-flowing regions due to the reduction in the daily accumulation of 


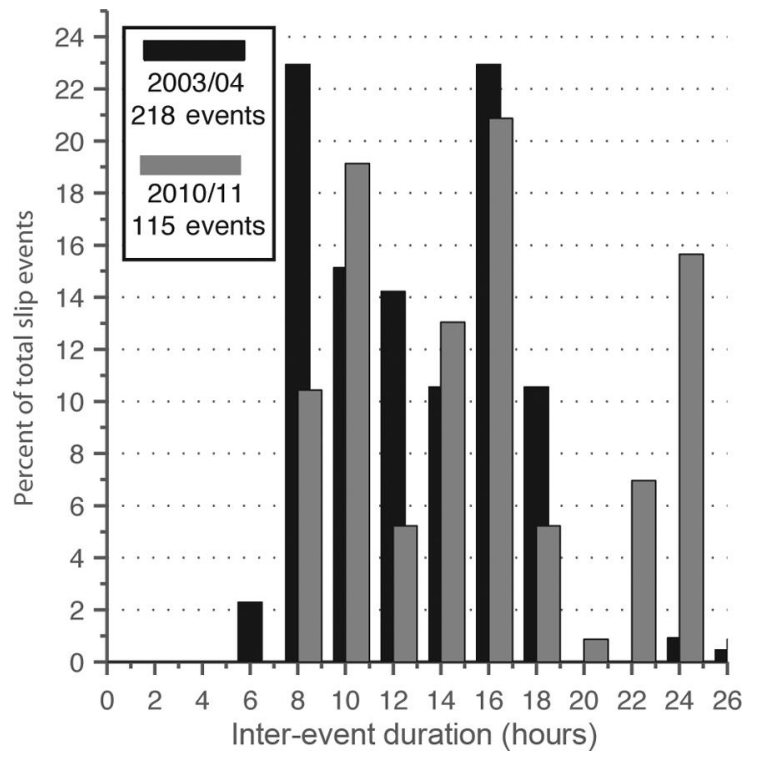

Fig. 8. Histogram of inter-event durations preceding slip events observed during the 2003/04 and 2010/11 field campaigns. Note the increase in long inter-event (>20 hours) durations in 2010/11 resulting from frequent skipped low-tide events.

strain. However, the deceleration observed near the CSS (W3B, 15\%) was significantly higher than in non-stick-slip locations (B190, 5\%) between 2003/04 and 2010/11.

A conspicuous change in WIS's behavior that coincided with this relatively rapid deceleration was the increase in the frequency of skipped events (Fig. 4). This change in behavior is reflected in the substantial increase in long inter-event periods ( $>20$ hours) in the 2010/11 dataset, occurring on $\sim 40 \%$ of days vs $\sim 1 \%$ in $2003 / 04$ (Fig. 8). During our observations, we recorded skips for low-tide events only; no skipped high-tide events were observed. As noted in previous studies and reviewed earlier, slip events following longer inter-event duration move farther; however, more motion is lost when a low-tide event is skipped than the extra slip in the following event, so that skips are associated with reduced average velocity. For example, during a neap tide, motion over the center of the ice stream (station W2B) is typically accommodated by two slip events that each follow a $\sim 12$ hour inter-event period, each resulting in $\sim 0.47 \mathrm{~m}$ of displacement (Fig. 6), for a total of $\sim 0.94 \mathrm{~m}$ of stick-slip motion during 24 hours. However, a slip event following an entire of day of dormancy moves only $\sim 0.68 \mathrm{~m}$, a $28 \%$ reduction in total motion.

The reduction in motion on single slip-event days accounts for the higher rates of deceleration observed in the stick-slip portion of WIS between 2003/04 and 2010/11. A similar relationship between inter-event duration and slip event displacement during 2004 and 2010 (Fig. 6) reveals that on normal days, those with two slip events, total motion was similar during each campaign. A linear regression through the data suggests a small downward shift in the trend ( $\sim 2 \mathrm{~cm}$ per slip event) between 2004 and 2010, that corresponds to $\sim 2 \%$ reduction in mean flow speed; however, this effect is small compared to the influence of the relative abundance of skipped low-tide events (40\% of days). The lower motion during single-slip-event days accounts for two-thirds of the $60 \mathrm{~m} \mathrm{a}^{-1}$ mean flow speed reduction (from $405 \mathrm{~m} \mathrm{a}^{-1}$ to $345 \mathrm{~m} \mathrm{a}^{-1}$ ) observed at station W2B between 2004 and 2010 (Figs 2 and 7), accounting for the higher rate of deceleration than observed upstream (i.e. station B190). Thus, while the long-term trend of deceleration is probably related to the strengthening of the icestream bed, the more-rapid deceleration between 2004 and 2010 was promoted by the increasing frequency of skipped events. Likewise, the relative stability of flow speed between 1997 (and perhaps earlier) and 2004 was likely sustained by the stability of the twice-daily stick-slip regime.

\subsection{Elevation changes from ICESat}

Our findings of unsteady deceleration prompted us to revisit the evolution of WIS as recorded by the Ice, Cloud and land Elevation Satellite (ICESat) mission (Abshire and others, 2005). The ICESat mission provides 18 snapshots (averaged over $\sim 1$ month periods) from early 2003 until late 2009, thus spanning the transition from low to high deceleration rates recorded in the velocity observations. Several previous studies have evaluated elevation changes on WIS in an attempt to better understand the current deceleration (Bindschadler and others, 2005; Csatho and others, 2005; Smith and others, 2005; Pritchard and others, 2009). Additionally, ICESat's frequent repeat observations allowed for the discovery of an interconnected system of active subglacial lakes on the downstream portion of the ice stream (Fricker and others, 2007).

We estimate surface-elevation change by measuring the difference between crossovers from different ICESat operational periods. Higher spatial resolution can be obtained by exploiting ICESat's high along-track sampling $(65 \mathrm{~m}$ footprints every $172 \mathrm{~m}$ ); however, this analysis is complicated by technical issues that resulted in repeat tracks being offset by up to hundreds of meters (Pritchard and others, 2009). Fortunately, the proximity of WIS to the orbital limit of ICESat results in a relatively abundant and spatially extensive dataset of crossovers ( $\sim 4$ points per $25 \mathrm{~km}^{2}$ during each operational period). This spatial density is sufficient for a regional assessment, so we employed this approach.

We use ICESat Release 33 and correct for Gaussiancentroid range errors introduced by transmit-pulse reference selection using data and software obtained from the US National Snow and Ice Data Center (Borsa and others, 2014). We did not use any data points located above previously identified subglacial lakes. Firn corrections were not applied to the observed elevations due to the relatively small errors $(<0.2 \mathrm{~m})$ expected to be introduced for this region (Pritchard and others, 2012). Spurious data points were identified automatically as any point measurements differing by $>10 \mathrm{~m}$ from the ICESat-derived digital elevation model (Bamber and others, 2009). We assessed the accuracy of the crossover analysis by calculating the standard deviation of crossovers for single laser periods; the $30 \mathrm{~cm}$ value is similar to previously published values (Smith and others, 2005) and sufficiently small that the pattern of changes detected between periods is highly significant. We calculated all surface elevation changes relative to the second ICESat laser operation period (operational period L2A October 2003), the earliest operational period that provides a relatively high degree of spatial coverage. Figure 9 shows the elevation changes for WIS between late 2003 (operational period L2A) and early 2009 (operational period L2E), interpolated onto a $2 \mathrm{~km}$ grid and smoothed at $20 \mathrm{~km}$.

As expected, the data clearly show development of a prominent surface-elevation change feature on WIS, a broad regional bulge $\sim 1.5 \mathrm{~m}$ high at the junction between the 


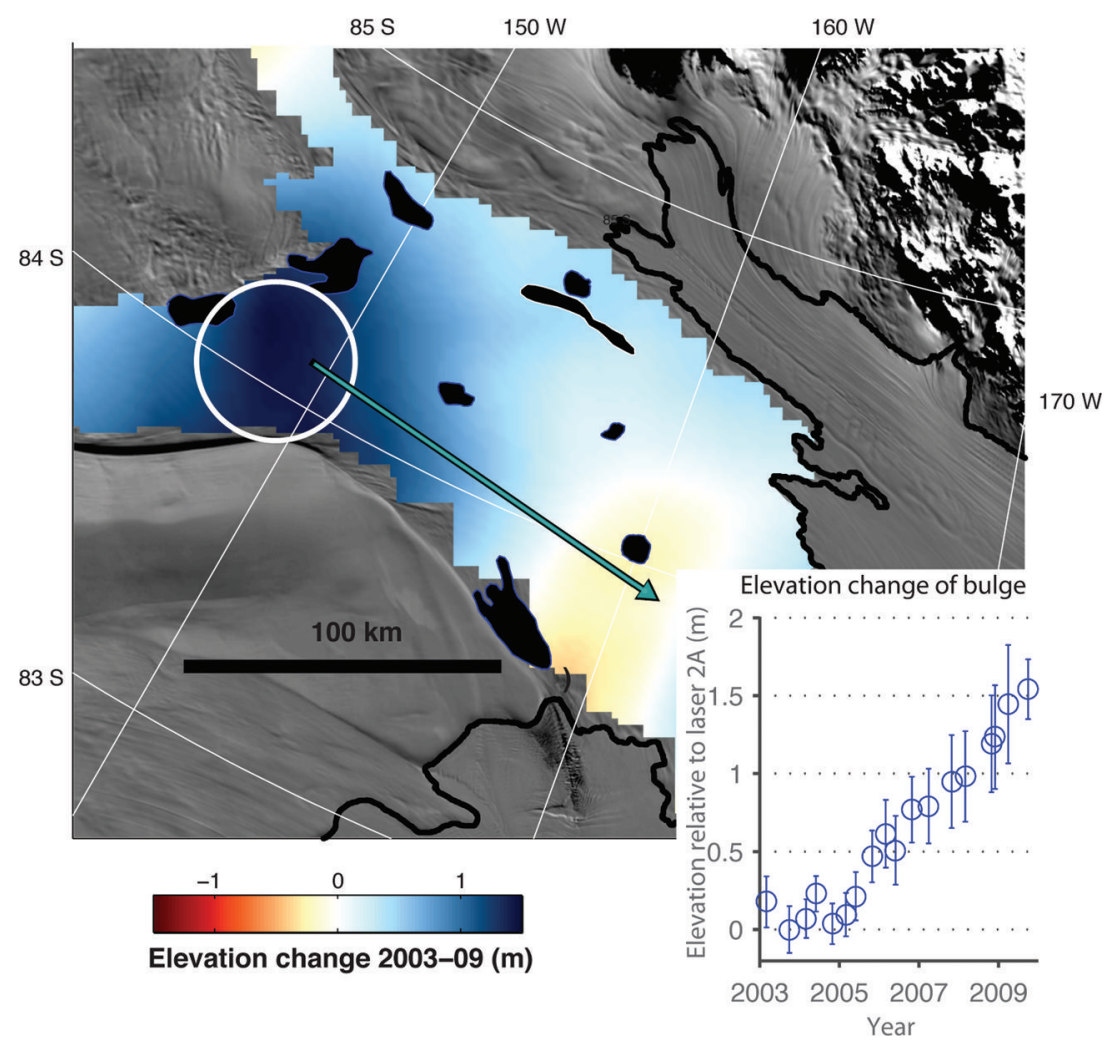

Fig. 9. Elevation change on WIS measured by the ICESat mission. Inset shows the temporal evolution of the surface elevations outlined by the circle. Black polygons outline known active subglacial lakes (Fricker and others, 2007).

main tributary and the ice plain (Fig. 9; Pritchard and others, 2009; Carter and others, 2013). This feature has been documented in earlier studies and reflects the higher rates of deceleration downstream vs upstream. To investigate any relationship between the rate of bulge growth and the previously described time variations in deceleration rate, we extracted a time series of relative elevations for a region of $25 \mathrm{~km}$ radius centered on the fastest-growing part of the bulge (Fig. 9). This time series shows minimal change in the early ICESat period (2003-06), followed by thickening $\left(\sim 0.3 \mathrm{~m} \mathrm{a}^{-1}\right)$ during the later period (2006-10). While we lack detailed velocity measurements between 2004 and 2009, the inflection in the elevation-change time-series data occurred at about the same time that the rate of deceleration and the number of skipped events began to increase downstream. As discussed below, physical understanding shows that these events should be linked. In turn, this suggests that the increased rate of deceleration downstream began towards the end of 2005 (Fig. 7b).

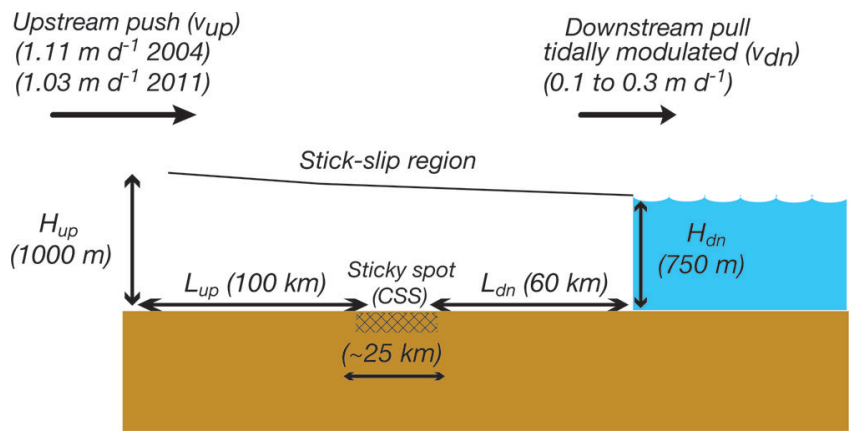

Fig. 10. Simplified conceptual model of WIS.

\subsection{Slip efficiency and viscoelasticity}

To understand the observed changes in behavior of WIS, we follow previous studies and model the force budget leading to the initiation of a slip event. The stress evolution on WIS sticky spot can be calculated assuming a simplified geometry of the ice stream, in which stresses on the sticky spot arise from compression upstream and extension downstream (Fig. 10). Our previous work (Bindschadler and others, 2003; Winberry and others, 2009, 2011) relied on a simple elastic model of stress evolution.

$$
\tau_{\text {sticky-spot }}=\frac{E W H_{\text {up }} x_{\text {up }}}{L_{\text {up }} A_{\text {sticky-spot }}}+\frac{E W H_{\mathrm{dn}} x_{\mathrm{dn}}}{L_{\mathrm{dn}} A_{\text {sticky-spot }}}
$$

where $\tau_{\text {sticky-spot }}$ is shear stress on the sticky spot CSS, $E$ is the Young's modulus of ice $\left(8.3 \times 10^{9} \mathrm{~Pa}\right.$; Gold, 1958), $x_{\text {up }}$ and $x_{\mathrm{dn}}$ are inter-event motion at the upstream and downstream end of the stick-slip region since the previous slip event, $H_{\text {up }}$ $(1000 \mathrm{~m})$ and $H_{\mathrm{dn}}(750 \mathrm{~m})$ are the average ice thickness upstream and downstream of the sticky spot respectively, while $L_{\text {up }}(100 \mathrm{~km})$ and $L_{\mathrm{dn}}(60 \mathrm{~km})$ are the length upstream and downstream of the sticky spot respectively and $W$ is the average width of the ice stream $(\sim 100 \mathrm{~km})$. Unlike earlier studies, in this work we have isolated the location of the main sticky spot and distribute the shear stress across the area of the CSS, $A_{\text {sticky-spot }}\left(\sim 500 \mathrm{~km}^{2}\right)$, instead of the ice stream's entire stick-slip length, as it appears to provide most of the resistance between slip events (Fig. 3a).

Motivated by the observed changes in stick-slip cycle and thickening at the upstream end of the stick-slip region, we depart from earlier efforts and also consider a viscoelastic approach to estimating the evolving force budget prior to a slip event initiation. We may represent the viscoelastic rheology of the ice stream as a Maxwell material with the 


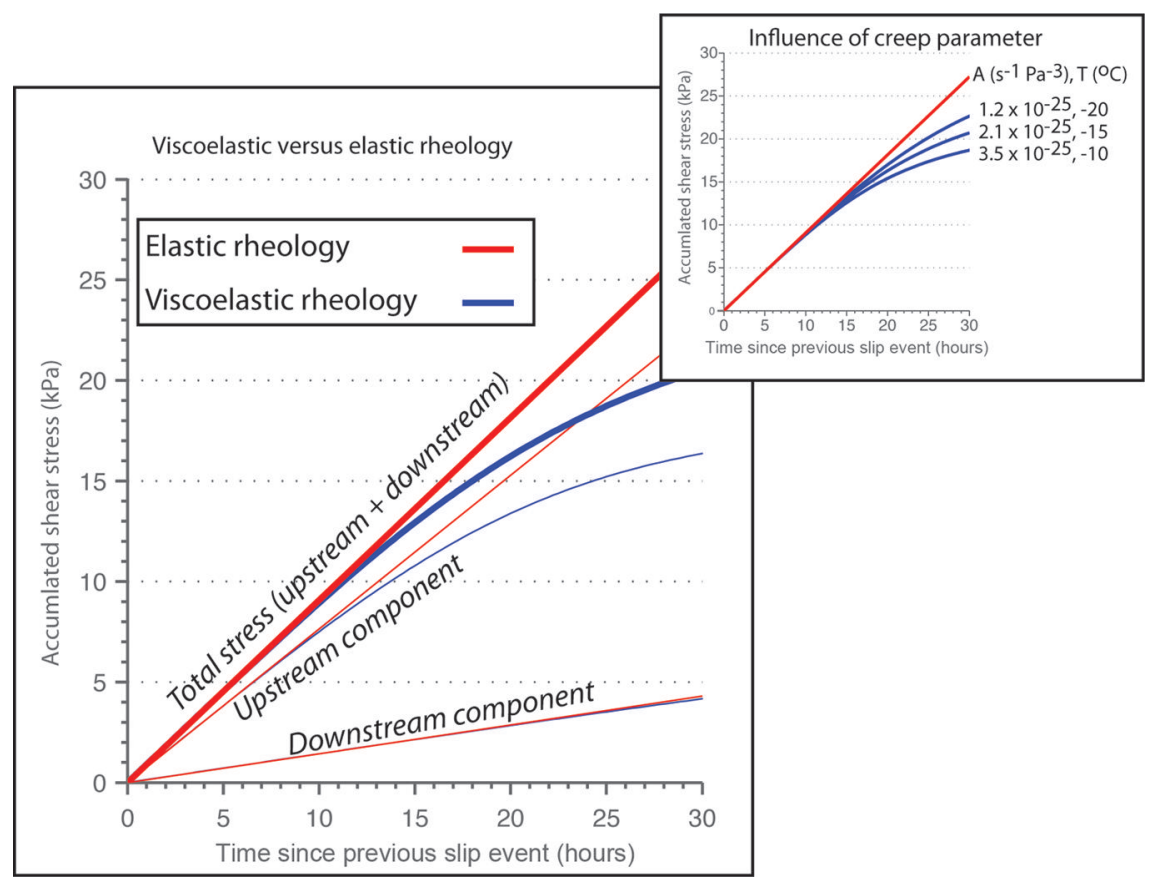

Fig. 11. Modeled evolution of sticky-spot basal shear stress following a slip event using an $A$ of $2.1 \times 10^{-25}\left(\mathrm{~s}^{-1} \mathrm{~Pa}^{-3}\right)$. Thin lines show the upstream and downstream components individually. The viscoelastic and elastic curves for the downstream component plot almost on top of each other because the viscous part of the downstream component is very small. Inset shows calculated stress evolution for various creep parameters.

differential equation for longitudinal compressive stress $\sigma$ and its time-derivative $\dot{\sigma}$

$$
\dot{\sigma}=E \dot{\varepsilon}-E A \sigma^{3}
$$

The first term on the right-hand side represents the elastic component of longitudinal deformation, and the second term is the viscous component (Glen's flow law), where $A$ is the flow law parameter $\left(2.1 \times 10^{-25} \mathrm{~s}^{-1} \mathrm{~Pa}^{-3}\right.$ for ice at $-15^{\circ} \mathrm{C}$, appropriate for WIS) (Joughin and others, 2002; Cuffey and Paterson, 2010). For WIS, we can estimate strain rate from upstream and downstream sources using

$$
\dot{\varepsilon}=\frac{V}{L}
$$

where $v$ is the velocity and $L$ is the length either upstream or downstream of the sticky spot (Fig. 10). Assuming that the applied stress is zero following the termination of a slip event, basal shear stress $\tau$ on the sticky spot is then estimated by summing the calculated upstream and downstream components of the applied stress

$$
\tau_{\text {sticky-spot }}=\frac{\sigma_{\text {up }} W H_{\text {up }}+\sigma_{\mathrm{dn}} W H_{\text {dn }}}{A_{\text {sticky-spot }}}
$$

To investigate the significance of a viscoelastic rheology for modeling the force budget during a WIS stick-slip cycle, we calculate the stress evolution during a 30 hour period following the termination of a slip event for both a viscoelastic and elastic model (Fig. 11). We impose an upstream velocity of $1 \mathrm{md}^{-1}$, representative of the flow upstream of the stick-slip region, and a downstream velocity of $0.15 \mathrm{md}^{-1}$, the upper limit for the tidally modulated downstream flow speed, to simplify the analysis. This analysis ignores the tidal pacing, but allows for an understanding of rheological controls on the ice stream's behavior. The total stress budget is plotted, as well as the upstream and downstream components. Similar to our previous work (Bindschadler and others, 2003; Winberry and others, 2009,
2011), the upstream component dominates the total stress budget, accounting for $\sim 75 \%$ of the total stress accumulation. Values are $\sim 5$ times higher than reported in our previous studies, because we are balancing the entire force on the CSS instead of distributing the force across the entire ice-stream bed. During the early stages of an inter-event period, the elastic and viscoelastic models are similar, because initially the stress is low so that viscous deformation, with its cubic dependence on stress, remains very low. Divergence between the elastic and viscoelastic models becomes evident in the region upstream of the sticky spot $\sim 15$ hours after the termination of a slip event. In contrast, the lower strain rates and associated stresses found downstream of the sticky spot cause the stress regime to be dominated by elastic processes even at relatively long interevent periods. Thus, while a simple elastic model accurately represents stress evolution of slip events initiating after interevent periods of less than $\sim 15$ hours, for longer time intervals viscous deformation becomes significant upstream of the sticky spot, reducing the rate of stress accumulation.

Motion in a stick-slip system, such as WIS, is linearly related to the amount of elastic strain released during slip events. However, the viscous deformation that occurs following a skipped low-tide event results in a net reduction in the total elastic strain (and stress drop) available for release during a day experiencing a single slip event. We observe from Figure 6 that during a slip event nucleating after 24 hours the ice stream moves $\sim 150 \%$ farther than an event nucleating after 12 hours, not $\sim 200 \%$ as would be expected with a doubling of strain accumulation in the elastic model. However, the viscoelastic calculation shows only a $150 \%$ increase in stress drop (19 vs $13 \mathrm{kPa}$ ), comparable to the displacement ratio observed between slip events occurring after 24 hours vs 12 hours (Fig. 6).

The exact amount of reduced stress drop resulting from the onset of viscous deformation will depend on the creep 


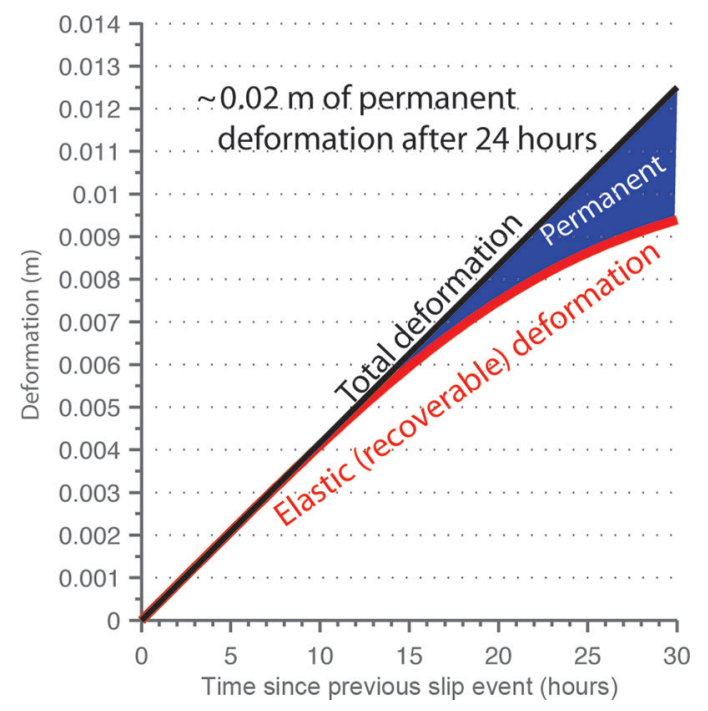

Fig. 12. Partitioning of vertical deformation upstream of sticky spot between elastic and viscous during an inter-event period.

parameter $A$. We examine this sensitivity by repeating the viscoelastic calculations for a range of creep parameters $\left(1.2-3.2 \times 10^{-25} \mathrm{~s}^{-1} \mathrm{~Pa}^{-3}\right)$ that encompass a plausible range of mean ice column temperatures $\left(-20\right.$ to $\left.-10^{\circ} \mathrm{C}\right)$ for WIS (Fig. 11). As expected, for colder, stiffer ice the deviation from a purely elastic model is less pronounced; however, all values of $A$ exhibit a reduction in stress levels beginning $\sim 15$ hours into a stick-slip cycle and a net reduction in applied shear stress for slip events nucleating following a 24 hour inter-event period.

The value of $E$ is also at least somewhat uncertain, as is the magnitude of additional stress supported on the sticky spot from flowlines in the ice stream that do not pass through the sticky spot. Thus, the magnitude of the viscous relaxation during longer inter-event times cannot be calculated precisely from the motion at the boundaries and material properties. Nonetheless, we can say with confidence that viscous deformation is significant for the longer inter-event times, providing a first-order explanation for the low total motion observed during single slip-event days.

This explanation predicts that the increasing skips will have caused net thickening upstream of the sticky spot. (Total ice motion during our study period is small compared to the length of the stick-slip region, and the ice stream is laterally constrained by ice ridges, so longitudinal compressive strain must be balanced by vertical extension.) Thickening is indeed observed (Fig. 9). We will briefly explore whether the viscous deformation between slip events associated with long inter-event periods following skipped low-tide events provides a quantitatively viable mechanism to explain the observed thickening between 2005 and 2009, while recognizing that the ICESat observations exhibit spatial complexity that will not be represented by our simple approximation of the ice stream.

To estimate thickening, we partitioned the average vertical deformation between elastic (recoverable during slip events) and viscous (permanent) deformation at the upstream end of the ice stream as a function of time since the previous slip event (Fig. 12). This was done by subtracting the viscous deformation from the total vertical deformation resulting from compression using the results presented in the main panel of Figure 11. After 24 hours

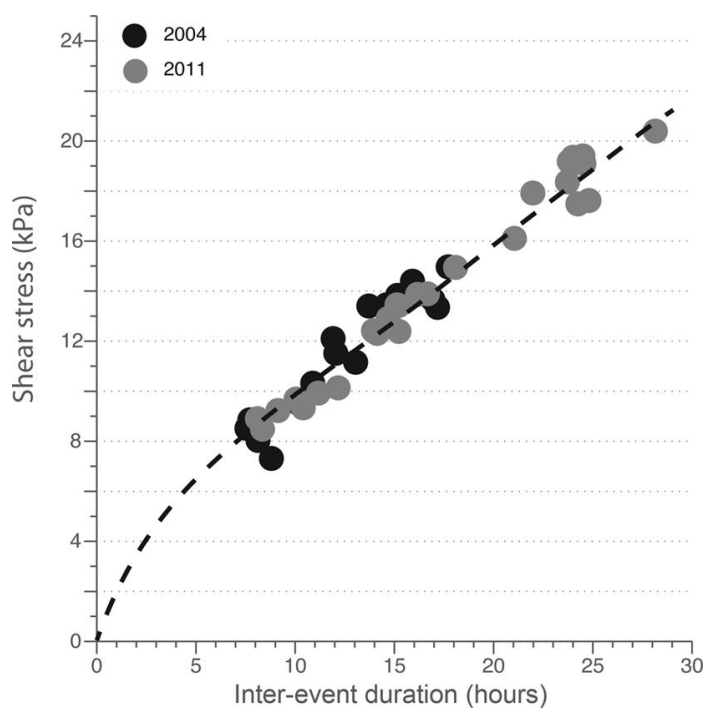

Fig. 13. Modeled accumulated (yield) shear stress on the CSS sticky spot for 2004 and 2011 events for which we had operational downstream GPS sites. Dashed line is the inferred trend interpolated to zero that is consistent with theoretical and laboratory studies.

since the previous slip event, $\sim 0.002 \mathrm{~m}$ (or 20\%) of the vertical deformation is permanent. In the 2010/11 datasets, single slip events were observed on $40 \%$ of days ( 150 slip events per year), leading to an annual thickening rate of $\sim 0.3 \mathrm{~m}$, comparable to that observed from ICESat. We could adjust the flow law parameter or other parameters to improve or degrade the fit; however, at the order-ofmagnitude level or better, the broad bulge forming at the upstream end of the ice stream can be attributed to viscous deformation during long inter-event periods.

\subsection{Mechanisms for the increasing number of skipped slip events}

We now consider the origin of the increased frequency of skipped low-tide events in the 2010/11 observations. The reduced frequency of slip events indicates a delay in reaching the basal yield stress and could be indicative of an increase in the strength of the sticky spot, a reduction in the rate of stress accumulation, or a combination of the two. To decipher the relative role of these effects, we use the viscoelastic model to calculate shear stress evolution preceding all slip events during the 10 days in 2004 and 20 days in 2011 that downstream locations were operational. No grounding-line sites were installed during 2003 and 2010. Due to the limited station coverage, we estimate the upstream strain rate using a steady inter-event velocity of $1.11 \mathrm{~m} \mathrm{~d}^{-1}$ in 2004 and $1.03 \mathrm{~m} \mathrm{~d}^{-1}$ in 2011 based on the 1997 and 2009 InSAR datasets. This accounts for the continued deceleration of steady-flowing regions upstream of the stick-slip region. The tidally modulated downstream strain rate is estimated from station W2A.

We first examine whether increases in sticky-spot strength are a viable mechanism to explain the increasing number of skipped slip events by calculating basal shear stress on the sticky spot at slip initiation (Fig. 13). This analysis confirms and extends previous work (Winberry and others, 2009; Walter and others, 2011) showing higher yield stress with longer waiting time, reflecting the progressive strengthening (or healing) of the ice/bed 

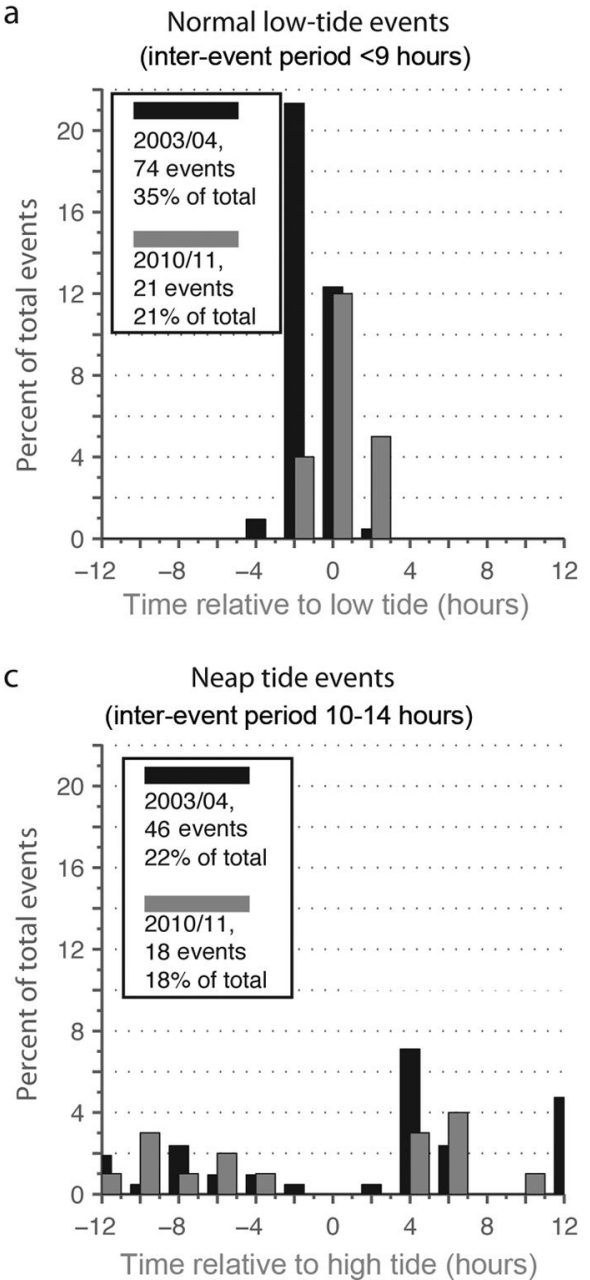

b

Normal high-tide events (inter-event period 14-19 hours)

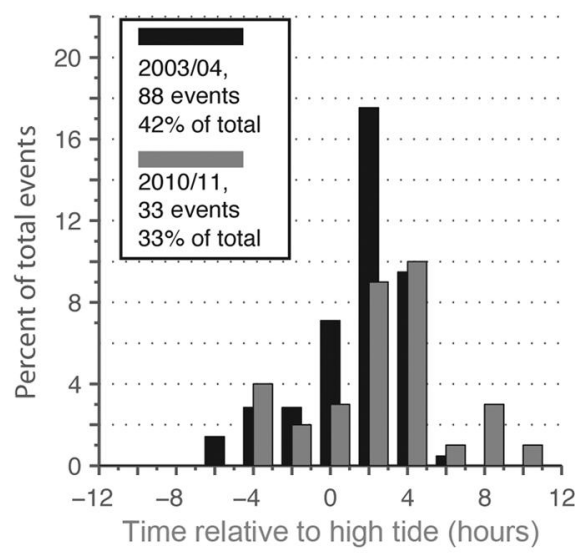

d Following skipped low-tide events (inter-event period $<19$ hours)

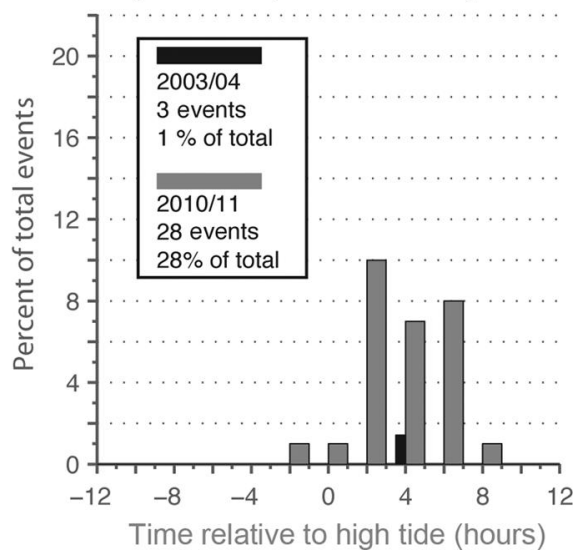

Fig. 14. Tidal phasing of slip events for (a) low tide, (b) high tide, (c) neap tide and (d) events following skipped low-tide events.

interface following each slip event; long inter-event times arising from skipped events were observed in 2011 but not 2004 in this dataset, explaining all of the high-stress events shown. An increase in the mean bed strength would result in a reduced amount of slip for a given amount of accumulated shear stress. However, we observe a consistent yield-stress/time relationship associated with the onset of slip event initiation during both 2004 and 2011, suggesting that the bed beneath the sticky spot did not undergo significant strengthening between the two time periods (Fig. 13). This is consistent with the relatively constant timeslip magnitude (Fig. 6), although scatter in the data makes small changes difficult to detect. We thus do not consider changes in the strength of the sticky spot to be the primary candidate for driving the increased frequency of skipped low-tide events. While the upstream portion of the ice stream continues to slow due to an increase in basal drag (e.g. Beem and others, 2014), the changes in mean strength of the stick-slip dominated region appear to be small $(<2-$ $3 \mathrm{kPa}$ between 2004 and 2011).

The other likely potential driver of the skipped slip events is a change in the inter-event stressing rate. In the absence of a modulated stressing rate (e.g. by the tides), slip events will typically be evenly spaced in time. Thus, the effect of a reduced stressing rate will be to increase the time separation between consecutive slip events. On WIS, deceleration of the upstream reach reduced the stressing rate on the sticky spot (CSS) by $\sim 0.06 \mathrm{kPah}^{-1}\left(0.94 \mathrm{vs} 0.88 \mathrm{kPah}^{-1}\right.$ ) between
2004 and 2011. As a result of this lower stressing rate, 12 hours into an inter-event period during 2011 the accumulated shear stress was $\sim 0.72 \mathrm{kPa}$ lower than in 2004. From Figure 14, we observe that the modeled bed strength increases by $\sim 0.7 \mathrm{kPah}^{-1}$ during both 2004 and 2011. Thus, the reduced 2011 stressing rate will on average delay onset of a slip event by $\sim 1$ hour relative to 2004 .

To assess the role of reduced stressing rates in the dynamics of the tidally modulated WIS, we have classified slip events into four major categories based on the interevent duration preceding the slip event: low tide ( $<9$ hours), normal high tide (14-19 hours), neap tide (10-14 hours) and those following skipped low tides (>19 hours) (Fig. 14). We then measured the time lag between slip-event initiation and either the low tide (low-tide events) or high tide (all other events) of the Ross Sea. While scatter is present in the data, clear shifts in timing are observed that are consistent with the reduced inter-event stressing rate. On average, low-tide events are delayed by 1-2 hours, initiating closer to low tide in 2010/11 relative to 2003/04. Likewise, high-tide events are shifted away from high tide by a similar amount. In both sets of observations neap-tide events display no strong phasing with the tides, while events following skipped lowtide events tend to nucleate following the subsequent high tide. A more subtle change, which is likely the result of a reduced stressing rate, is the shift in the amount of time required to initiate a slip event from $\sim 6$ to $\sim 8$ hours between 2003/04 and 2010/11 (Fig. 8). 
This increase in inter-event duration coupled with sensitivity of slip initiation to the tidal modulation of downstream inter-event motion (Fig. 5) generates more favorable conditions for the skipping of low-tide events in 2010/11. First, the reduced loading has the effect of delaying high-tide events by $\sim 1$ hour (Fig. 14). Since high-tide events typically nucleate on the falling tide, the result is to lower the time over which rapid downstream motion may increase stress on the sticky spot to initiate the subsequent low-tide event. Second, as with the high-tide event, lower upstream loading delays initiation by an additional $\sim 1$ hour. Thus, the combined effect of the delayed high-tide event coupled with lower inter-event stressing rate is to shift low-tide events from typically nucleating $\sim 2$ hours before the low tide in 2003/04 to near low tide in 2010/11 (Fig. 14), increasing the probability that a slip event will not be initiated prior to the rising tide. Subsequent to the low tide, continued strengthening of the sticky spot may outpace the decreased stressing rates associated with a rising tide, increasing the likelihood of a skipped low-tide event.

\section{SUMMARY}

We have investigated the complex behavior of the decelerating WIS. We have isolated the location of the large sticky spots that hinder stable flow in the stick-slip portion of the ice stream. The sticky spots are situated on broad ( $\sim 40 \mathrm{~km}$ radius) highs in the subglacial hydropotential that preferentially divert water into surrounding large subglacial lakes. The relatively low surface slopes presently found on the ice plain favor the formation of such large subglacial lakes that will promote localized storage of subglacial water and the formation of large sticky spots. Additionally, recent work shows that the large bulge forming at the upstream end of the stick-slip region influences the drainage paths between the subglacial lakes beneath WIS (Carter and others, 2013). These results provide further evidence that the coupled evolution of large sticky spots and subglacial lakes may play a crucial role in understanding the dynamic behavior of the ice stream (Fricker and others, 2010; Sergienko and Hulbe, 2011).

The onset of stick-slip motion due to the development of large sticky spots ( $>20 \mathrm{~km}$ diameter) has a fundamental influence on ice-stream behavior during stagnation. In traditional models of oscillatory ice-stream behavior (Payne, 1998; Bougamont and others, 2003), evolution of local thermal conditions and associated changes in basal drag regulate the evolution of surface flow speed. In contrast to this expectation, the basal shear strength of the main sticky spot on WIS appears to be undergoing minimal or no change, suggesting that the subglacial till beneath this region is sufficiently depleted of water that no significant evolution of porosity and strength is occurring. However, we have shown that the stick-slip-style behavior that dominates the downstream portion of the ice stream introduces unsteadiness in the deceleration, not due to local conditions, but through interactions with the steady-flowing but decelerating upstream portions of the ice stream. It is possible that in the future, low-tide slip events will become completely absent. In such a scenario, it is likely that deceleration in the downstream portion of the ice stream will decrease to a rate comparable to that observed upstream of the stick-slip region.

It is becoming increasingly clear that processes characterized by a range of timescales influence the evolution of ice sheets. Our work provides further evidence of how shorttimescale (days to months) processes can influence longerterm evolution (decades to centuries) of an ice sheet. While the large-scale stick-slip style of motion is unique among active ice streams, the low driving stress conditions that make stick-slip possible were likely common in past configurations of the West Antarctic ice sheet when lowslope ice streams extended outward to the continental shelf (Denton and Hughes, 2002). Additionally, unsteadiness in behavior at short timescales in response to small perturbations, such as documented here, provides unique windows into the fundamental physics of glaciers and ice sheets.

\section{ACKNOWLEDGEMENTS}

We thank Alex Brisbourne, Peter Burkett, Angela Hoffer, Randy Justin, Tarun Luthra and Stephanie Kay for help with data collection in 2010 and 2011, and the entire TIDES team for data collection efforts in 2003 and 2004. GPS data were processed using Natural Resources Canada's PPP-direct service. Instrumentation and support was provided by the University Navstar Consortium (UNAVCO) instrument center. Logistical support was provided by Raytheon Polar Services, the New York Air National Guard and Kenn Borek Air. Ross Sea tides were computed using software provided by Laurence Padman. We thank investigators as well as the US National Snow and Ice Data Center for making ICESat, MODIS, InSAR and Siple Coast Project datasets publicly available. Two anonymous reviews improved the quality of the presentation. This work was supported by the US National Science Foundation Office of Polar Programs grant 0944794.

\section{REFERENCES}

Abshire JB and 7 others (2005) Geoscience Laser Altimeter System (GLAS) on the ICESat Mission: on-orbit measurement performance. Geophys. Res. Lett., 32(21), L21S02 (doi: 10.1029/ 2005GL024028)

Alley RB (1993) In search of ice-stream sticky spots. J. Glaciol., 39(133), 447-454

Anandakrishnan S, Voigt DE, Alley RB and King MA (2003) Ice Stream $D$ flow speed is strongly modulated by the tide beneath the Ross Ice Shelf. Geophys. Res. Lett., 30(7), 1361 (doi: 10.1029/2002GL016329)

Bamber JL, Gomez-Dans JL and Griggs JA (2009) A new 1 km digital elevation model of the Antarctic derived from combined satellite radar and laser data - Part 1: data and methods. Cryosphere, 3(1), 101-111 (doi: 10.5194/tc-3-101-2009)

Beem LH, Tulaczyk SM, King MA, Bougamont M, Fricker HA and Christoffersen P (2014) Variable deceleration of Whillans Ice Stream, West Antarctica. J. Geophys. Res., 119(F2), 212-224 (doi: 10.1002/2013JF002958)

Bindschadler R (1993) Siple Coast Project research of Crary Ice Rise and the mouths of Ice Streams B and C, West Antarctica: review and new perspectives. J. Glaciol., 39(133), 538-552

Bindschadler RA, King MA, Alley RB, Anandakrishnan $\mathrm{S}$ and Padman L (2003) Tidally controlled stick-slip discharge of a West Antarctic ice stream. Science, 301(5636), 1087-1089 (doi: 10.1126/science.1087231)

Bindschadler R, Vornberger P and Gray L (2005) Changes in the ice plain of Whillans Ice Stream, West Antarctica. J. Glaciol., 51(175), 620-636 (doi: 10.3189/172756505781829070)

Blankenship DD, Bentley CR, Rooney ST and Alley RB (1987) Till beneath Ice Stream B. 1. Properties derived from seismic travel times. J. Geophys. Res., 92(B9), 8903-8911 (doi: 10.1029/ JB092iB09p08903) 
Borsa AA, Moholdt G, Fricker HA and Brunt KM (2014) A range correction for ICESat and its potential impact on ice-sheet mass balance studies. Cryosphere, 8(2), 345-357 (doi: 10.5194/tc-8345-2014)

Bougamont M, Tulaczyk S and Joughin I (2003) Numerical investigations of the slow-down of Whillans Ice Stream, West Antarctica: is it shutting down like Ice Stream C? Ann. Glaciol., 37, 239-246 (doi: 10.3189/172756403781815555)

Carter SP, Fricker HA and Siegfried MR (2013) Evidence of rapid subglacial water piracy under Whillans Ice Stream, West Antarctica. J. Glaciol., 59(218), 1147-1162 (doi: 10.3189/ 2013JoG13J085)

Csatho B and 8 others (2005) ICESat measurements reveal complex pattern of elevation changes on Siple Coast ice streams, Antarctica. Geophys. Res. Lett., 32(23), L23S04 (doi: 10.1029/ 2005GL024289)

Cuffey KM and Paterson WSB (2010) The physics of glaciers, 4th edn. Butterworth-Heinemann, Oxford

Denton GH and Hughes TJ (2002) Reconstructing the Antarctic ice sheet at the Last Glacial Maximum. Quat. Sci. Rev., 21(1-3), 193-202 (doi: 10.1016/S0277-3791(01)00090-7)

Fretwell P and 59 others (2013) Bedmap2: improved ice bed, surface and thickness datasets for Antarctica. Cryosphere, 7(1), 375-393 (doi: 10.5194/tc-7-375-2013)

Fricker HA and Scambos T (2009) Connected subglacial lake activity on lower Mercer and Whillans Ice Streams, West Antarctica, 2003-2008. J. Glaciol., 55(190), 303-315 (doi: 10.3189/002214309788608813)

Fricker HA, Scambos T, Bindschadler R and Padman L (2007) An active subglacial water system in West Antarctica mapped from space. Science, 315(5818), 1544-1548 (doi: 10.1126/ science.1136897)

Fricker HA, Scambos T, Carter S, Davis C, Haran T and Joughin I (2010) Synthesizing multiple remote-sensing techniques for subglacial hydrologic mapping: application to a lake system beneath MacAyeal Ice Stream, West Antarctica. J. Glaciol., 56(196), 187-199 (doi: 10.3189/002214310791968557)

Gold LW (1958) Some observations on the dependence of strain on stress for ice. Can. J. Phys., 36(10), 1265-1275

Gudmundsson $\mathrm{GH}$ (2006) Fortnightly variations in the flow velocity of Rutford Ice Stream, West Antarctica. Nature, 444(7122), 1063-1064 (doi: 10.1038/nature05430)

Hulbe C and Fahnestock M (2007) Century-scale discharge stagnation and reactivation of the Ross ice streams, West Antarctica. J. Geophys. Res., 112(F3), F03S27 (doi: 10.1029/2006JF000603)

Iverson NR (2010) Shear resistance and continuity of subglacial till: hydrology rules. J. Glaciol., 56(200), 1104-1114 (doi: 10.3189/ 002214311796406220)

Joughin I and 7 others (1999) Tributaries of West Antarctic ice streams revealed by RADARSAT interferometry. Science, 286(5438), 283-286 (doi: 10.1126/science.286.5438.283)

Joughin I, Tulaczyk S, Bindschadler RA and Price S (2002) Changes in West Antarctic ice stream velocities: observation and analysis. J. Geophys. Res., 107(B11), 2289 (doi: 10.1029/2001JB001029)

Joughin I and 10 others (2005) Continued deceleration of Whillans Ice Stream, West Antarctica. Geophys. Res. Lett., 32(22), L22501 (doi: 10.1029/2005GL024319)

Kamb B (2001) Basal zone of the West Antarctic ice streams and its role in lubrication of their rapid motion. In Alley RB and Bindschadler RA eds. The West Antarctic ice sheet: behavior and environment. (Antarctic Research Series 77) American Geophysical Union, Washington, DC, 157-199

Marone C (1998) Laboratory-derived friction laws and their application to seismic faulting. Annu. Rev. Earth Planet. Sci., 26, 643-696 (doi: 10.1146/annurev.earth26.1.643)

Padman L, Erofeeva S and Joughin I (2003) Tides of the Ross Sea and Ross Ice Shelf cavity. Antarct. Sci., 15(1), 31-40 (doi: 10.1017/ S0954102003001032)

Parizek BR, Alley RB, Anandakrishnan S and Conway H (2002) Subcatchment melt and long-term stability of Ice Stream D, West
Antarctica. Geophys. Res. Lett., 29(8), 551-554 (doi: 10.1029/ 2001GL014326)

Payne AJ (1998) Dynamics of the Siple Coast ice streams, West Antarctica: results from a thermomechanical ice sheet model. Geophys. Res. Lett., 25(16), 3173-3176 (doi: 10.1029/ 98GL52327)

Pratt MJ, Winberry JP, Wiens DA, Anandakrishnan S and Alley RB (2014) Seismic and geodetic evidence for grounding-line control of Whillans Ice Stream stick-slip events. J. Geophys. Res., 119(F2), 333-348 (doi: 10.1002/2013JF002842)

Pritchard HD, Arthern RJ, Vaughan DG and Edwards LA (2009) Extensive dynamic thinning on the margins of the Greenland and Antarctic ice sheets. Nature, 461(7266), 971-975 (doi: 10.1038/nature08471)

Pritchard HD, Ligtenberg SRM, Fricker HA, Vaughan DG, Van den Broeke MR and Padman L (2012) Antarctic ice-sheet loss driven by basal melting of ice shelves. Nature, 484(7395), 502-505 (doi: 10.1038/nature10968)

Rignot E, Mouginot J and Scheuchl B (2011) Ice flow of the Antarctic Ice Sheet. Science, 333(6048), 1427-1430 (doi: 10.1126/science.1208336)

Scambos TA, Haran TM, Fahnestock MA, Painter TH and Bohlander J (2007) MODIS-based Mosaic of Antarctica (MOA) data sets: continent-wide surface morphology and snow grain size. Remote Sens. Environ., 111(2-3), 242-257 (doi: 10.1016/ j.rse.2006.12.020)

Scheuchl B, Mouginot J and Rignot E (2012) Ice velocity changes in the Ross and Ronne sectors observed using satellite radar data from 1997 and 2009. Cryosphere, 6(5), 1019-1030 (doi: 10.5194/tc-6-1019-2012)

Sergienko OV and Hulbe CL (2011) 'Sticky spots' and subglacial lakes under ice streams of the Siple Coast, Antarctica. Ann. Glaciol., 52(58), 18-22 (doi: 10.3189/172756411797252176)

Sergienko O, MacAyeal DR and Bindschadler RA (2009) Stick-slip behavior of ice streams: modeling investigations. Ann. Glaciol., 50(52), 87-94 (doi: 10.3189/172756409789624274)

Shabtaie S and Bentley CR (1987) West Antarctic ice streams draining into the Ross Ice Shelf: configuration and mass balance. J. Geophys. Res., 92(B2), 1311-1336 (doi: 10.1029/ JB092iB02p01311)

Shreve RL (1972) Movement of water in glaciers. J. Glaciol., 11(62), 205-214

Smith BE, Bentley CR and Raymond CF (2005) Recent elevation changes on the ice streams and ridges of the Ross Embayment from ICESat crossovers. Geophys. Res. Lett., 32(21), L21S09 (doi: 10.1029/2005GL024365)

Stearns LA, Jezek KC and Van der Veen CJ (2005) Decadal-scale variations in ice flow along Whillans Ice Stream and its tributaries, West Antarctica. J. Glaciol., 51(172), 147-157 (doi: 10.3189/172756505781829610)

Stephenson SN and Bindschadler RA (1988) Observed velocity fluctuations on a major Antarctic ice stream. Nature, 334(6184), 695-697 (doi: 10.1038/334695a0)

Vogel SW and 7 others (2005) Subglacial conditions during and after stoppage of an Antarctic Ice Stream: is reactivation imminent? Geophys. Res. Lett., 32(14), L14502 (doi: 10.1029/ 2005GL022563)

Walter JI, Brodsky EE, Tulaczyk S, Schwartz SY and Pettersson R (2011) Transient slip events from near-field seismic and geodetic data on a glacier fault, Whillans Ice Plain, West Antarctica. J. Geophys. Res., 116(F1), F01021 (doi: 10.1029/2010JF001754)

Whillans IM, Bolzan J and Shabtaie S (1987) Velocity of Ice Streams B and C, Antarctica. J. Geophys. Res., 92(B9), 8895-8902 (doi: 10.1029/JB092iB09p08895)

Wiens DA, Anandakrishnan S, Winberry JP and King MA (2008) Simultaneous teleseismic and geodetic observations of the stickslip motion of an Antarctic ice stream. Nature, 453(7196), 770-774 (doi: 10.1038/nature06990)

Winberry JP, Anandakrishnan S, Alley RB, Bindschadler RA and King MA (2009) Basal mechanics of ice streams: insights 
from the stick-slip motion of Whillans Ice Stream, West Antarctica. J. Geophys. Res., 114(F1), F01016 (doi: 10.1029/ 2008JF001035)

Winberry JP, Anandakrishnan S, Wiens DA, Alley RB and Christianson K (2011) Dynamics of stick-slip motion, Whillans Ice Stream, Antarctica. Earth Planet. Sci. Lett., 305(3-4), 283-289 (doi: 10.1016/j.epsl.2011.02.052)

Zoet LK, Anandakrishnan S, Alley RB, Nyblade AA and Wiens DA (2012) Motion of an Antarctic glacier by repeated tidally modulated earthquakes. Nature Geosci., 5(9), 623-626 (doi: $10.1038 /$ ngeo1555)

Zoet LK and 6 others (2013) The effects of entrained debris on the basal sliding stability of a glacier. J. Geophys. Res., 118(F2), 656-666 (doi: 10.1002/jgrf.20052)

Zumberge JF, Heflin MB, Jefferson DC, Watkins MM and Webb FH (1997) Precise point positioning for the efficient and robust analysis of GPS data from large networks. J. Geophys. Res., 102(B3), 5005-5017 (doi: 10.1029/96JB03860)

MS received 21 February 2014 and accepted in revised form 19 June 2014 